\title{
Literatura e realismo em György Lukács: os efeitos da inflexão marxista em suas ideias estéticas
}

Cotrim, Ana (2016).

Prefacio de Miguel Vedda; Porto Alegre, Zouk; 424 pp.

ISBN 9788580490350

\section{María Belén Castano}

CONICET, Universidad de Buenos Aires, Argentina

La presentación del riguroso volumen de Ana Cotrim no solo contribuye a la divulgación sobre el legado estético de la década de 1930, que forma parte de un período crucial en la constitución del pensamiento de György Lukács, uno de los filósofos más influyentes del siglo XX -cuyas malas interpretaciones han ocasionado muchas veces una dificultad en su circulación-, sino que también se destaca por el análisis crítico sobre las reflexiones de prestigiosos intelectuales contemporáneos marxistas como José Chasin, Carlos Nelson Coutinho, Celso Frederico, Béla Királyfalvi, Leandro Konder, Michael Löwy, Werner Mittenzwei, Francisco Posada, Nicolas Tertulian y Miguel Vedda.

Ana Cotrim es Doctora en Filosofía en la Universidad de San Pablo y Profesora de estética marxista en la Universidad de Brasilia. El libro, que es el resultado de la investigación de la Maestría en Filosofía realizada entre 2006 y 2009 en el Departamento de Filosofía de la Universidad de San Pablo, con la dirección del Profesor Franklin Leopoldo e Silva, no está traducido aún al español. Su objeto principal gira en torno al concepto de realismo artístico en la ensayística de Lukács de la década de 1930, que se distancia de las concepciones estéticas expresadas en su obra de juventud. Para dicho análisis, se aborda la importancia fundamental que cumple el giro marxista de naturaleza ontológica en los últimos años de 1920 de Lukács, en el que se profundizan los elementos fundantes del ser social descubierto por Marx. Se considera aquí la evolución de la teoría del realismo presente en las perspectivas estéticoliterarias que emergen de esa década, opuestas a las tendencias dominantes de los movimientos revolucionarios de la época y en la que se pueden identificar aquellos elementos futuros que profundizan su tratamiento en las obras tardías del autor de Teoría de la novela. El elemento central que se analiza en los textos abordados en este libro permite comprender cómo en el complejo de formulaciones que constituye el realismo de Lukács cobran relevancia aquellos elementos literarios centrales, que tornan posible el reflejo y que pueden ser sintetizados en las determinaciones de la acción en su relación orgánica con lo típico. Cotrim procura, en este minucioso análisis, abordar ese complejo de determinaciones que constituyen el realismo y presentar el camino que Lukács siguió para alcanzarlo, destacando la centralidad de la acción y su fundamentación objetiva en la praxis.

Vital para el giro marxista de Lukács es la lectura de los Manuscritos de París de Marx, cuyo impacto intelectual supondrá un aporte significativo para su concepción filosófica. De ahí que el estudio sobre el análisis de Marx referido al fenómeno de la alienación, así como la postulación de la presencia de una esencia genérica (Gattungswesen) que, aunque subyugada bajo las condiciones históricas particulares del capitalismo, perdura de manera latente, forzaron a Lukács a una revisión de sus presupuestos teóricos (Salinas, 2015: 52). Si en los Manuscritos, Marx había cuestionado la propuesta hegeliana de suprimir toda objetividad, el hombre real tiene que realizar su propia esencia objetivando sus facultades esenciales (Wesenskräfte) a través de la producción de un mundo material, externo: "este acto de exteriorización de las propias capacidades a través del trabajo es la prueba, la confirmación de la facultad creadora del hombre" 
(Vedda, 2006: 64). De este modo, resulta elemental la consideración acerca de que "lo que debe superarse no es la objetivación (Vergegenständlichung) en sí, sino tan sólo una de sus formas históricas: la alienación (Entfremdung)" (ídem).

El análisis de Cotrim comienza con dos aspectos principales: el primero aborda el comienzo del proceso de madurez de Lukács que inicia a fines de los años 1920, cuyo momento esencial se basa en el descubrimiento de los Manuscritos de 1844. El segundo punto trata la producción que, en la década de 1930, el filósofo húngaro desarrolla de un pensamiento estético y literario, apoyado en las determinaciones marxistas y en una concepción artística basada en el realismo. El pensamiento juvenil con el que Lukács rompe y que le permite acercarse a Marx en su madurez, en palabras de la autora, se trata de un "nuevo comienzo", que el mismo Lukács designa como el pasaje de una clase social a otra (Cotrim, 2016: 36).

En su exposición, Cotrim presenta ciertas nociones literarias desde 1930, que conformarían un "primer momento de desarrollo" que llevará a Lukacs a defender el realismo, a partir de un camino que revela un proceso de comprensión cada vez más preciso del fenómeno artístico en su relación intrínseca con el mundo. Aquí, Cotrim examina, además de la cuestión de la objetividad del reflejo artístico y de la objetividad de la forma, otros ejes de reflexión como el partidismo, la defensa de la configuración y las críticas a las novelas de reportaje y al arte de "tendencia". La autora se detiene en particular en "El debate entre Marx-Engels y Lasalle sobre el Franz von Sickingen", el primer texto estético-literario de Lukács de los años treinta, escrito en 1930 y publicado en 1933; cuatro ensayos publicados en Linkskurve, "Las novelas de WilliBredel" (1931)" "¿Tendencia o partidismo?" (1932) y “¿Reportaje o configuración? Observaciones críticas con ocasión de la novela de Ottwalt"; "De la necesidad, una virtud" (1932); y "Arte y verdad objetiva" (1934).

La autora examina más tarde la concepción estética de Lukács tal como se expone en los textos escritos a partir de fines de 1934, en los que, en la teoría del realismo, alcanza una determinación central la acción, en su relación con la tipicidad. Se analizan aquí las discusiones planteadas en dos ensayos publicados en los Escritos de Moscú, "Nota sobre la novela" (1934) y "La novela como epopeya burguesa" (1935); y “¿Narrar o describir?" (1936). Finalmente, el libro se cierra con las reflexiones que Lukács plantea en "Marx y el problema de la decadencia ideológica" (1938) sobre los efectos de la división capitalista del trabajo en la subjetividad del individuo burgués, que subyace en la ideología de la decadencia y en las condiciones subjetivas para la creación realista. De este último tema, Cotrim profundiza la relación que el filósofo húngaro establece entre la peculiaridad del arte y los problemas de la individualidad creadora en el período de la decadencia, a partir de la defensa por el humanismo.

El libro contiene un prefacio de Miguel Vedda "Sobre a centralidade de ação e o 'realismo bem entendido'" (La centralidad de la acción y del "realismo bien entendido"), en el que se subraya la importancia de este estudio que desmiente las formulaciones erróneas por parte de numerosos intelectuales contemporáneos que vinculan al filósofo húngaro con la teoría y la praxis estalinista y se resalta el examen crítico y preciso que la autora realiza sobre la producción lukacsiana de la década del 1930. Vedda se detiene en la importancia del énfasis de Cotrim sobre el "viraje ontológico" iniciado a comienzos de dicha década, como un punto de inflexión decisivo, que permitió a Lukács romper con las tendencias voluntaristas presentes en su etapa anterior, alcanzando un conocimiento más profundo sobre el legado de Marx, a raíz del cual avanza hacia territorios poco explorados por el pensamiento marxista anterior. Asimismo, destaca la capacidad de Cotrim de discutir en forma inteligente a partir de posiciones autónomas la bibliografía existente sobre Lukács y el hecho de que se ocupa exhaustivamente de un análisis de obras anteriores como Teoría de la novela (1914-15; publicado como libro en 1920); Historia y conciencia de clase (1923) - y posteriores- Sobre la particularidad como categoría estética (1954-56; publicado como libro en 1967), Introducción a una estética marxista (1960,1975), La peculiaridad de lo estético (1963). 


\section{Bibliografía}

»Salinas, M. (2015). Lukács y una lectura del carácter desfetichizador del arte (acerca de El engaño de las cartas, de Gotfried Keller). En Vedda, M.; G. Costa y N. Alcântara (eds.), Anúario Lukács 2015, pp. 51-62. San Pablo: Instituto Luckács.

»Vedda, M. (2006). György Lukács y la fundamentación ontológica de lo estético. En Vedda, M., La sugestión de lo concreto, pp. 57-103. Buenos Aires: Gorla. 